\title{
UMA DISCUSSÃO SOBRE A PUNIÇÃO AOS DESCENDENTES DO TRANSGRESSOR
}

\section{A DISCUSSION ON THE PUNISHMENT TO THE TRANSGRESSOR'S \\ DESCENDANTS}

Manu Marcus Hubner*

\section{Resumo}

Este artigo discute se as transgressões dos pais provocam consequências ou até mesmo punições aos seus filhos, netos e bisnetos, descendentes até a terceira ou quarta gerações, segundo a ótica da Bíblia Hebraica.

Palavras-chave: Bíblia Hebraica, Pecado, Transgressão, Gerações, Visita

\begin{abstract}
This article discusses whether the transgressions of parents cause consequences or even punishment to their children, grandchildren and great-grandchildren, descendants until the third or fourth generations, from the perspective of the Hebrew Bible.
\end{abstract}

Keywords: Hebrew Bible, Sin, Transgression, Generations, Visit

\footnotetext{
* Doutor em Letras pelo Programa de Pós-graduação em Estudos Judaicos e Árabes do Departamento de Letras Orientais da Faculdade de Filosofia, Letras e Ciências Humanas da Universidade de São Paulo.
} 
Viver durante três gerações, até conhecer os próprios netos, é um sinal de bênção divina, segundo a Bíblia Hebraica ${ }^{1}$ :

Coroa dos velhos são os filhos dos filhos... $(\operatorname{Pr} 17: 6)^{2}$

O SENHOR te abençoe desde Sião, para que vejas a prosperidade de Jerusalém durante os dias de tua vida, vejas os filhos de teus filhos. Paz sobre Israel! (Sl 128:5-6)

A Bíblia Hebraica enfatiza a existência de personagens que receberam o mérito de conhecer seus netos.

Então, disse Israel a José: Eu não cuidara ver o teu rosto; e eis que Deus me fez ver os teus filhos também. (Gn 48:11)

José habitou no Egito, ele e a casa de seu pai; e viveu cento e dez anos. Viu José os filhos de Efraim até à terceira geração; também os filhos de Maquir, filho de Manassés, os quais José tomou sobre seus joelhos. (Gn 50:22-23)

Então, as mulheres disseram a Noemi: Seja o SENHOR bendito, que não deixou, hoje, de te dar um neto que será teu resgatador, e seja afamado em Israel o nome deste. (Ru 4:14)

Depois disto, viveu Jó cento e quarenta anos; e viu a seus filhos e aos filhos de seus filhos, até à quarta geração. (Jó 42:16)

Mas, por outro lado, filhos, netos e bisnetos, descendentes até a terceira ou até a quarta gerações, podem ser alvos da punição divina sobre a iniquidade dos antecessores.

Não terás outros deuses diante de Mim. Não farás para ti imagem de escultura, figura alguma do que há em cima, nos céus, e abaixo, na terra, e nas águas, debaixo da terra. Não te prostrarás diante deles, nem os servirás, pois Eu sou o Eterno, teu Deus, Deus zeloso, que visito a iniquidade dos pais nos filhos, sobre terceiras e sobre quartas gerações, aos que Me aborrecem, e faço misericórdia até duas mil gerações aos que Me amam e aos que guardam Meus mandamentos. (Ex 20:3-6; Dt 5:7-10, grifo nosso)

...visita a iniquidade dos pais nos filhos e nos filhos dos filhos, sobre terceiras e quartas gerações. (Ex 34:7b, grifo nosso)

\footnotetext{
${ }^{1}$ A Bíblia Hebraica é composta pelos 24 livros do Pentateuco, Profetas e Escritos.

${ }^{2}$ As abreviações dos livros da Bíblia Hebraica seguem o padrão da Bíblia de Jerusalém. A não ser quando indicado de outra forma, a Bíblia utilizada para citações do Pentateuco neste trabalho será a Torá: A Lei de Moisés. Trad. Meir Matzliah Melamed. São Paulo: Sefer, 2001. Para citações dos demais livros da Bíblia Hebraica, será utilizada A Bíblia Sagrada. Trad. João Ferreira D’Almeida, edição revista e atualizada do site Bible Hub.
} 
A passagem acima, “...visito a iniquidade dos pais nos filhos, sobre terceiras e sobre quartas gerações...” encontra eco em outras passagens bíblicas:

Os pais comeram uvas verdes, e os dentes dos filhos se embotaram. (Jr 31:29; Ez 18:2)

Nossos pais pecaram, e já não existem; e nós levamos as suas iniquidades. (Lm 5:7)

Há exemplos, na Bíblia Hebraica, de punições que atingem, além do culpado, outros membros de sua família ou pessoas de seu povo.

Durante o período de liderança de Josué, Acã confessa seu roubo. As consequências são fatais para Acã, juntamente com sua família e até mesmo seus animais.

Respondeu Acã a Josué: Verdadeiramente pequei contra o Senhor Deus de Israel, e eis o que fiz: quando vi entre os despojos uma boa capa babilônica, e duzentos siclos de prata, e uma cunha de ouro do peso de cinqüenta siclos, cobicei-os e tomei-os; eis que estão escondidos na terra, no meio da minha tenda, e a prata debaixo da capa. (Js 7:20-21)

Então Josué e todo o Israel com ele tomaram Acã, filho de Zerá, e a prata, a capa e a cunha de ouro, e seus filhos e suas filhas, e seus bois, jumentos e ovelhas, e a sua tenda, e tudo quanto tinha, e levaram-nos ao vale de Acor. E disse Josué: Por que nos perturbaste? Hoje o Senhor te perturbará a ti: E todo o Israel o apedrejou; queimaram-nos no fogo, e os apedrejaram. (ibid., $7: 24-25)$

Doegue, seguindo as ordens do rei Saul, matou os sacerdotes suspeitos de colaborarem com David, e destruiu Nobe, a cidade destes sacerdotes, com seus moradores e até mesmo os animais.

Então disse o rei [Saul] a Doegue: Vira-te e arremete contra os sacerdotes. Virou-se, então, Doegue, o edomeu, e arremeteu contra os sacerdotes, e matou naquele dia oitenta e cinco homens que vestiam éfode de linho. Também a Nobe, cidade desses sacerdotes, passou a fio de espada; homens e mulheres, meninos e criancinhas de peito, e até os bois, jumentos e ovelhas passou a fio de espada. (1 Sm 22: 18-19)

O rei David entregou sete descendentes do rei Saul para a vingança dos gibeonitas. 
Disse-lhes Davi: Que quereis que vos faça? Responderam ao rei: Quanto ao homem que nos consumia, e procurava destruir-nos, de modo que não pudéssemos subsistir em termo algum de Israel, de seus filhos se nos dêem sete homens, para que os enforquemos ao Senhor em Gibeá de Saul, o eleito do Senhor. E o rei disse: Eu os darei. (2 Sm 21:4-6)

Mas o rei tomou os dois filhos de Rizpa, filha de Aías, que ela tivera de Saul, a saber, a Armoni e a Mefibosete, como também os cinco filhos de Merabe, filha de Saul, que ela tivera de Adriel, filho de Barzilai, meolatita, e os entregou na mão dos gibeonitas, os quais os enforcaram no monte, perante o Senhor; e os sete caíram todos juntos. (ibid., 21:8-9)

Segundo a profecia de Amós, a família de Amazias, o sacerdote que expulsou Amós de Betel, terá um trágico fim, assim como o povo do reino de Israel.

E respondeu Amós, e disse a Amazias: Eu não sou profeta, nem filho de profeta, mas boieiro, e cultivador de sicômoros. Mas o Senhor me tirou de após o gado, e o Senhor me disse: Vai, profetiza ao meu povo Israel. Agora, pois, ouve a palavra do Senhor: Tu dizes: Não profetizes contra Israel, nem fales contra a casa de Isaque. Portanto assim diz o Senhor: Tua mulher se prostituirá na cidade, e teus filhos e tuas filhas cairão à espada, e a tua terra será repartida a cordel; e tu morrerás numa terra imunda, e Israel certamente será levado cativo para fora da sua terra. (Am 7:14-17)

Este costume de punir os filhos pelo pecado dos pais também está presente no Código de Hammurabi (1728-1686 A. E. C.), rei da antiga Babilônia.

If a seignior struck a(nother) seignior's daughter and has caused her to have a miscarriage, he shall pay ten shekels of silver for her fetus. (Lei ${ }^{\circ} 209$ )

If that woman has died, they shall put his daughter to death. (Lei $\mathrm{n}^{\circ} 210$ )

(The Code of Hammurabi. Trad. Theophile J. Meek, apud Pritchard, 2011, p. 175)

As consequências da iniquidade dos pais atingindo os filhos aparentemente contrasta com a lei bíblica de que cada um deve pagar pelo seu próprio pecado.

Não se fará morrer os pais pelo testemunho dos filhos, nem os filhos pelo testemunho dos pais. Cada homem pelo seu pecado morrerá. (Dt 24:16)

Não serão mortos os pais por causa dos filhos, nem os filhos por causa dos pais; mas cada um será morto pelo seu próprio pecado. (2 Rs 14:6b)

O mesmo conceito de justiça pode ser encontrado no épico mesopotâmico de Gilgamesh: 
On the sinner impose his sin,

On the transgressor impose his transgression!

(The Epic of Gilgamesh, Trad. E. A. Speiser, apud Pritchard, 2011, p. 68)

Portanto há, nestes trechos, uma aparente contradição: se um homem, e somente ele, deve pagar por seus pecados, como seria possível a punição divina recair sobre seus filhos, netos e bisnetos?

Segundo o Talmud, o julgamento divino sobre o mundo é feito de forma coletiva:

Because the world is judged by its majority, and an individual [too] is judged by his majority [of deeds, good or bad], if he performs one good deed, happy is he for turning the scale both for himself and for the whole world on the side of merit; if he commits one transgression, woe to him for weighting himself and the whole world in the scale of guilt, for it is said: but one sinner, etc. on account of the single sin which this man commits he and the whole world lose much good. (Talmud Kiddushin 40b)

Portanto, esta contradição pode ser explicada pelo conceito da recompensa e responsabilidade coletivas ${ }^{3}$. Existem vínculos estreitos de responsabilidade coletiva especialmente entre membros de uma família, como também da família perante Deus. Esta responsabilidade coletiva poderia estender-se até a uma cidade ou reino. Portanto, o pecado de um rei pode trazer calamidades a seu povo, conforme atestam os exemplos dos reis do Egito e de Gerar, da época de Abraão, e do rei Saul, de Israel.

E infligiu o Eterno ao Faraó e à sua casa, grandes pragas por causa de Sarai, mulher de Abrão. (Gn 12:17)

...porque tinha fechado Deus toda matriz da casa de Abimélech, por causa de Sara, mulher de Abrahão. (Gn 20:18)

Porquanto não deste ouvidos à voz do Senhor, e não executaste e furor da sua ira contra Amaleque, por isso o Senhor te fez hoje isto. E o Senhor entregará também a Israel contigo na mão dos filisteus. Amanhã tu e teus filhos estareis comigo, e o Senhor entregará o arraial de Israel na mão dos filisteus. (1 Sm 28:18-19)

\footnotetext{
${ }^{3}$ Kaufmann (1989, p. 332-333).
} 
Na visão dos profetas de Israel, transgressões morais não constituem pecados sujeitos ao julgamento no âmbito individual, mas acarretam a punição coletiva de Deus, como destruição nacional e exílio.

Portanto, a injustiça social de alguns pode provocar o sofrimento de toda a nação.

Ouvi isto, vós que pisais os necessitados, e destruís os miseráveis da terra, dizendo: Quando passará a lua nova, para vendermos o grão? e o sábado, para expormos o trigo, diminuindo a medida, e aumentando o preço, e procedendo dolosamente com balanças enganadoras, para comprarmos os pobres por dinheiro, e os necessitados por um par de sapatos, e para vendermos o refugo do trigo? Jurou o Senhor pela glória de Jacó: Certamente nunca me esquecerei de nenhuma das suas obras. Por causa disso não estremecerá a terra? e não chorará todo aquele que nela habita? (Am 8:4-8)

E o que suceder ao povo, sucederá ao sacerdote; ao servo, como ao seu senhor; à serva, como à sua senhora; ao comprador, como ao vendedor; ao que empresta, como ao que toma emprestado; ao que recebe usura, como ao que paga usura. (Is 24:2)

A soberba das elites pode levar à guerra e destruição.

Diz ainda mais o Senhor: Porquanto as filhas de Sião são altivas, e andam de pescoço emproado, lançando olhares impudentes; e, ao andarem, vão de passos curtos, fazendo tinir os ornamentos dos seus pés; (...)

Teus varões cairão à espada, e teus valentes na guerra. $\mathrm{E}$ as portas da cidade gemerão e se carpirão e, desolada, ela se sentará no pó. (Is 3:16, 25-26)

A opressão dos mais fracos pode levar à destruição da nação.

Ai daqueles que promulgam leis iníquas, e todos que elaboram decretos opressores, a fim de privar os pobres dos seus direitos e evitar que os oprimidos do meu povo tenham pleno acesso à justiça, transformando as viúvas em presas de suas ambições e despojando os órfãos! Pois bem, que fareis no Dia do Castigo, quando a destruição vier de um lugar distante, mas certeira? A quem correreis em busca de abrigo e socorro, onde deixareis as vossas riquezas, para não terdes de vos arrastar humilhantemente entre os prisioneiros, para não cairdes entre os cadáveres? Mesmo assim, a ira divina ainda não se desviou; sua mão continua, pois, estendida para punir. "Ai da Assíria, a vara da minha ira, em cujas mãos está o bastão do meu juízo!...” (Is 10:1-5)

E a injustiça pode levar ao exílio. 
Ele ansiava por justiça, mas houve apenas derramamento de sangue inocente; esperava pela prática do direito, mas o que viu foi o povo clamando por socorro! Ai dos que ajuntam casas e mais casas, dos que acrescentam um campo a outro, até que não haja mais onde alguém possa erguer sua casa, e eles se tornem os senhores absolutos da terra! (...)

Portanto, o meu povo será levado cativo ao exílio, por falta de sabedoria; os seus nobres passarão fome e a multidão se secará de sede. (Is 5:7-8, 13)

Os seus chefes dão as sentenças por peitas, e os seus sacerdotes ensinam por interesse, e os seus profetas adivinham por dinheiro; e ainda se encostam ao Senhor, dizendo: Não está o Senhor no meio de nós? nenhum mal nos sobrevirá. Portanto, por causa de vós, Sião será lavrada como um campo, e Jerusalém se tornará em montões de pedras, e o monte desta casa em lugares altos dum bosque. (Mq 3:11-12)

Por outro lado, a simples presença de algumas pessoas justas tem o potencial de ajudar ou de salvar pessoas ímpias.

Se encontrar em Sodoma cinquenta justos dentro da cidade, perdoarei ao lugar todo, por causa deles. (...)

...talvez se encontrem ali dez. E disse: "Não destruirei pelos dez." (Gn 18:26, $32 b)$

Consequentemente, Labão é beneficiado pela sua associação com Jacob, assim como Potifar, com José.

E disse-lhe Labão: Se, por favor, tenho conseguido graças, aos teus olhos, (fica) pois adivinhei que me bendisse o Eterno por tua causa. (Gn 30:27)

E foi então, quando o encarregou sobre sua casa e tudo o que tinha, abençoou o Eterno a casa do egípcio por causa de José; e foi a bênção do Eterno em tudo que ele tinha, na casa e no campo. (Gn 39:5)

Todas as famílias do mundo serão abençoadas através de um só homem, Abraão: “... e serão benditas em ti todas as famílias da terra” (Gn 12:3).

A responsabilidade coletiva não é aceita com facilidade pelos personagens bíblicos.

E aproximou-se Abrahão e disse: Destruirás também o justo com o mau? (...) Longe de ti de fazer tal coisa, de matar o justo com o mau; e será assim o justo igual ao mau; longe de Ti! Aquele que é juiz de toda a terra, não fará justiça? (Gn 18:23, 25) 
E atiraram-se [Moisés e Aarão] sobre seus rostos e disseram: Ó Deus! Deus dos espíritos de toda criatura! Se um homem pecar, contra toda a companhia te indignarás? (Nm 16:22)

E, vendo Davi ao anjo que feria o povo, falou ao Senhor, dizendo: Eis que eu pequei, e procedi iniquamente; porém estas ovelhas, que fizeram? Seja, pois, a tua mão contra mim, e contra a casa de meu pai. (2 Sm 24:17)

Em resumo, o destino de cada homem está ligado ao destino de seus familiares; os atos de seus parentes, de seus compatriotas e até mesmo de seu rei podem afetá-10 ${ }^{4}$.

Além da conduta de cada indivíduo poder afetar a vida da comunidade, a conduta de uma geração também impacta as gerações subsequentes 5 . Desta forma, Deus "visita" a iniquidade de uma geração sobre as próximas - o que significa infligir punição pela culpa de uma geração sobre seus descendentes ${ }^{6}$; ou faz "misericórdia até duas mil gerações" - o que significa recompensar os descendentes pela lealdade e obediência dos ancestrais ${ }^{7}$, para aqueles que são fiéis aos seus mandamentos.

Se más ações funcionam como más influências para os descendentes de um malfeitor, seja por hereditariedade ou por imitação, a influência de boas ações é muito mais potente, já que o alcance da recompensa é de duas mil gerações, enquanto o alcance da punição é de apenas quatro gerações ${ }^{8}$.

É interessante notar que a longevidade natural que um ser humano pode atingir vai até a terceira ou a quarta geração de descendentes; portanto, a punição divina é estendida apenas aos descendentes que o culpado provavelmente verá. O sofrimento dos descendentes torna-se, então, um meio de intimidação ou uma punição do ancestral, e não uma transferência da sua culpa para os seus descendentes ${ }^{9}$.

Os profetas Jeremias e Ezequiel reviram esse conceito da punição que atravessa gerações, e sentiram-se compelidos a negá-lo, devido ao receio de criar-se uma sensação de desesperança e apatia em uma época de crise nacional ${ }^{10}$ :

Naqueles dias não dirão mais: Os pais comeram uvas verdes, e os dentes dos filhos se embotaram. Pelo contrário, cada um morrerá pela sua própria

\footnotetext{
${ }^{4}$ Kaufmann (1989, p. 332-333).

${ }^{5}$ Sarna (The JPS Torah Commentary: Exodus, 1991, p. 110).

${ }^{6}$ Tigay (The JPS Torah Commentary: Deuteronomy, 1996, p. 110).

${ }^{7}$ Ibid.

${ }^{8}$ Hastings (Dictionary of the Bible, 1909, p. 906).

${ }_{9}^{9}$ Tigay (The JPS Torah Commentary: Deuteronomy, 1996, p. 110).

${ }^{10}$ Sarna (The JPS Torah Commentary: Exodus, 1991, p. 110).
} 
iniqüidade; de todo homem que comer uvas verdes, é que os dentes se embotarão. (Jr 31:29-30)

Que quereis vós dizer, citando na terra de Israel este provérbio: Os pais comeram uvas verdes, e os dentes dos filhos se embotaram? Vivo eu, dize Senhor Deus, não se vos permite mais usar deste provérbio em Israel. Eis que todas as almas são minhas; como o é a alma do pai, assim também a alma do filho é minha: a alma que pecar, essa morrerá. (Ez 18:2-3)

Contudo dizeis: Por que não levará o filho a iniqüidade do pai? Ora, se o filho proceder com retidão e justiça, e guardar todos os meus estatutos, e os cumprir, certamente viverá. A alma que pecar, essa morrerá; o filho não levará a iniquidade do pai, nem o pai levará a iniquidade do filho, A justiça do justo ficará sobre ele, e a impiedade do ímpio cairá sobre ele. (Ez 18:1920)

Esta opinião é corroborada pelo Talmud como se Ezequiel revogasse uma parte de um mandamento do Decálogo ${ }^{11}$ :

Moses had said, The Lord is . . . visiting the iniquity of the fathers upon the children and upon the children's children, unto the third and unto the fourth generation $^{12}$; Ezekiel came and declared, the soul that sinneth, it shall $\mathrm{die}^{13}$. (Talmud Makkoth 24a)

O Talmud reitera que um indivíduo pode ser punido pelos pecados de seus pais, apenas quando ele próprio segue o caminho escolhido pelos pais.

Are not children then to be put to death for the sins committed by their parents? Is it not written, Visiting the iniquities of the fathers upon the children? There the reference is to children who follow their parentes' footsteps. (Talmud Sanhedrin 27b)

Para consumar a ideia de que cada homem recebe recompensa ou punição apenas em decorrência de seus próprios atos, e não dos atos de outros, Ezequiel utiliza-se do exemplo de três eminentes personagens bíblicos: Noé, Daniel e Jó. Ezequiel considera essas três personalidades como exemplos de justiça, livres de pecados, e afirma que punição coletiva alguma os atingiria. Entretanto, pecadores destituídos do padrão de retidão desses três personagens não teriam a mesma sorte, mesmo estando próximos.

\footnotetext{
${ }^{11}$ Ibid., p. 111.

${ }^{12}$ Cf. Ex 34:7.

${ }^{13} \mathrm{Cf}$. Ez 18:3.
} 
Filho do homem, quando uma terra pecar contra mim, agindo traiçõeiramente, então estenderei a minha mão contra ela, e lhe quebrarei o báculo do pão, e enviarei contra ela a fome, e dela exterminarei homens e animais; ainda que estivessem no meio dela estes três homens, Noé, Daniel e Jó, eles pela sua justiça, livrariam apenas a sua própria vida, diz o Senhor Deus. Se eu fizer passar pela terra bestas feras, e estas a assolarem, de modo que ela fique desolada, sem que ninguém possa passar por ela por causa das feras; ainda que esses três homens estivessem no meio dela, vivo eu, diz o Senhor Deus, que nem a filhos nem a filhas livrariam; eles só ficariam livres; a terra, porém, seria assolada. Ou, se eu trouxer a espada sobre aquela terra, e disser: Espada, passa pela terra; de modo que eu extermine dela homens e animais; ainda que aqueles três homens estivessem nela, vivo eu, diz o Senhor Deus, eles não livrariam nem filhos nem filhas, mas eles só ficariam livres. Ou, se eu enviar a peste sobre aquela terra, e derramar o meu furor sobre ela com sangue, para exterminar dela homens e animais; ainda que Noé, Daniel e Jó estivessem no meio dela, vivo eu, diz o Senhor Deus, eles não livrariam nem filho nem filha, tão somente livrariam as suas próprias vidas pela sua justiça. (Ez 14:13-20)

O verbo utilizado para referir-se às eventuais punições infligidas à terceira e à quarta

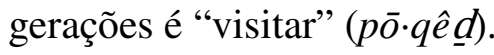

... visito a iniquidade dos pais nos filhos, sobre terceiras e sobre quartas gerações... (Ex 20:5; Dt 5:9)

...visita a iniquidade dos pais nos filhos e nos filhos dos filhos, sobre terceiras e quartas gerações. (Ex 34:7b).

O mesmo verbo é utilizado referindo-se à matriarca Sara, como também à Ana, mãe do profeta Samuel, para as quais Deus cumpre as suas promessas.

E o Eterno visitou a Sara, como disse, e fez o Eterno a Sara como falou. (Gn 21:1)

Visitou, pois, o Senhor a Ana, que concebeu... (1 Sm 2:21)

O termo $p \bar{o} \cdot q \hat{e} \underline{d}$ pode significar "visitar", "lembrar", "decretar", "contar/convocar", “confiar", comandar" ou "ordenar"14. Deus, portanto, "visita" ou "lembra" o pecado dos pais nas três ou quatro gerações seguintes, assim como nos exemplos acima, nos quais Deus cumpre as suas promessas para Sara e Ana.

\footnotetext{
${ }^{14}$ Jastrow (A Dictionary of the Targumim, The Talmud Babli and Yerushalmi, and the Midrashic Literature, 1996, p. 1206-1207).
} 
Assim, a partir das opiniões dos profetas Jeremias e Ezequiel e do Talmud, como também pelo termo escolhido pela Bíblia Hebraica para a transferência da punição de um pecado de pais para filhos - "visitar", podemos concluir que o pecado dos pais não ocasiona uma punição aos filhos; o pecado "visita" os filhos, netos e bisnetos, ou seja, os descendentes sofrem as consequências do pecado dos antecessores. Como exemplo, se um homem sofre pena de morte por algum motivo, seus filhos ficarão órfãos e seus netos não terão avós, mas, segundo a lei bíblica, filhos, netos e bisnetos não poderão pagar pelo crime do pai, porque "a alma que pecar, essa morrerá" (Ez 18:2-3). 


\section{Referências}

BÍBLIA. Português. A Bíblia Sagrada. Trad. João Ferreira D’Almeida. Rio de Janeiro: Sociedades Bíblicas Unidas, 1950.

BÍBLIA. Português. Bíblia de Jerusalém. $2^{a}$ impressão. São Paulo: Paulus, 2003.

BÍBLIA. Português. Torá: A Lei de Moisés. Trad. Meir Matzliah Melamed. São Paulo, Sefer, 2001.

HASTINGS, James. Dictionary of the Bible. New York: Charles Scribner's Sons, 1909.

JASTROW, Marcus [ed.]. A Dictionary of the Targumim, The Talmud Babli and Yerushalmi, and the Midrashic Literature. New York: The Judaica Press, 1996.

The JPS Torah Commentary: Deuteronomy. Comentários: Jeffrey H. Tigay. Philadelphia: The Jewish Publication Society, 1996.

Exodus. Comentários: Nahum M. Sarna. Philadelphia: The Jewish Publication Society, 1991.

KAUFMANN, Yehezkel. A Religião de Israel. Trad. Attílio Cancian. São Paulo: Perspectiva, Editora da Universidade de São Paulo, 1989.

\section{Softwares}

Bible Hub, Glassport (PA): Online Parallel Bible Project, 2013, disponível em: <biblos.com>.

Bible Works. Versão 5.0. Bigfork (MT): Hermeneutika Computer Bible Research Software, 2001.

Judaic Classics: The Soncino Talmud. Versão 3.4. New York: Judaica Press, 1990. 